2017 , volume 6, issue 2

Nagy, V. (2017). The role of the amount of money in risk-taking. Copernican Journal of Finance \& Accounting, 6(2), 45-58. http://dx.doi.org/10.12775/CJFA.2017.010

\author{
VIKTOR NAGY* \\ Obuda University
}

\title{
THE ROLE OF THE AMOUNT OF MONEY IN RISK-TAKING
}

Keywords: risk-taking, certainty, amount of money, personal decisions.

J E L Classification: D81, G32.

Abstract: Decisions based on the expected value have two components: the probability and the value or utility that is often expressed in money. Regarding the first element, it can be pointed out that many decisions contain risk concerning the outcomes of the available options, i.e. concerning the probability of the occurrence of an event. Uncertainty refers, in most cases, to this part, but having said that, the second part, the amount of money, still matters in a decision-making situation. Since the research of the effect of the amount can be considered neglected compared to that of probabilities, I focused on the second component: on the role of the amount of money. The aim was to explore to what extent a 300 times difference in the amount affects the choice.

\section{IIIINTRODUCTION}

Expected value is often used in probability theory to determine the optimal choice. The formula used for this is the following:

$$
E(X)=\sum_{i=1}^{N} p_{i} \cdot x_{i}
$$

Date of submission: July, 25, 2017; date of acceptance: October, 27, 2017.

* Contact information: nagy.viktor@kgk.uni-obuda.hu, Obuda University, Keleti Faculty of Business and Management, 1084 Budapest, Tavaszmező u. 17., Hungary, phone: +36-1-6665212. 
where:

- E(X): the expected value (of the event X) itself;

- N: the number of events/outcomes;

- $p_{i}$ : the probability of the i-th event occurring;

$-\mathrm{x}_{\mathrm{i}}$ : the positive or negative outcome of the $\mathrm{i}$-th event; it can be expressed in money or in utility and is required to be measured on ratio scale.

E.g.: suppose we have a box with well-mixed yellow, red, and blue cards. Based on the card drawn out of the box, it is decided whether the player wins or not (or loses) as listed below:

Table 1. Example of a probabilistic game

\begin{tabular}{|c|c|c|c|}
\hline \hline & Yellow & Red & Blue \\
\hline \hline Number of cards & 10 & 25 & 15 \\
\hline Wins/Losses & 100 & 0 & -10 \\
\hline \hline
\end{tabular}

S o u r c e : own study.

What is the average amount that can be won? It is the expected value, the sum product of the probabilities and values:

$$
E(X)=\frac{10}{10+15+25} \cdot 100+\frac{25}{10+15+25} \cdot 0+\frac{15}{10+15+25} \cdot(-10)=17
$$

The conclusions are very clear: playing this game many times, the mean of the winnings will be 17. Sometimes one wins (yellow card) sometimes one simply doesn't (red one), sometimes one loses (blues), but in the long term one definitely gains money. Therefore, if one can take part in this gamble for free and for unlimited times, one ought to do so. But it also means that a casino will never offer such a game unless the participation fee is higher than 17. Accurate probabilities and accurate outcomes result in well-founded decisions and one follows this well-understood interest. If only one opportunity is given to take part in the game, the expected value is not a datum that one can rely on. However, on the other hand, there are games where in cases of great expected value, one is not willing to pay either except for a small stake. A widely-known example is the Saint Petersburg paradox that I played with international students for years. The game is something like this: 
EUR 1 can be won and the game ends, if a flipped (of course fair) coin comes up heads. If it's tails, the winnings are doubled, and the coin is flipped again. In general, the winnings increase by doubling, till flipping results in heads. The question was: how much they were willing to pay to enter the game?

The expected value here:

$$
E(X)=\frac{1}{2} \cdot 1+\frac{1}{4} \cdot 2+\frac{1}{8} \cdot 4+\ldots=\frac{1}{2}+\frac{1}{2}+\frac{1}{2}+\ldots=\sum_{k=1}^{\infty} \frac{1}{2}=\infty
$$

Students tended not to pay more than two, three, or four euros for the opportunity to take part in the game despite the infinite amount of expected value. That is to say, based on the mathematical calculations all the money is worth it. They didn't even calculate the expected value although it was the topic right before.

In the beginning researches on risky decisions focused on the expected value i.e. utility. Theory of Games and Economic Behavior (by von Neumann \& Morgenstern, 1953) is one of the basic and widely known book that played an important role that time. Merely the fact itself, that it was reprinted and reedited many times in the second half of the 40s and in the first half of the $50 \mathrm{~s}$, could show its fundamental significance. Researches from that era was concentrating on the mathematical approaches. Later the center of interest changed so that the theories can better describe the real life choices. Although Allais (1953) also dealt with problems in which assumptions of utility theories can be questioned, in developing such new theories Kahneman and Tversky (1979) had a pioneering role. Since then, of course, these theories have more developed, successor theories. From that time new paradoxes are discussed (Birnbaum, 2008) too, but these usually are on violating other expectations of normative theories, or deal with some criticism. In my research I accepted that respondents do not behave based on logical rules and in a consistent way, my aim was not to set up new paradoxes and prove that decisions can be inconsistent in several cases, but I wanted to do some examination to observe the effect of a 300 times difference in the amount to the choice in risky situations.

In a decision situation usually the following matrix is used as a general model: 
Table 2. General payoff matrix

\begin{tabular}{|c|c|c|c|c|}
\hline \hline \multirow{2}{*}{ Actions } & \multicolumn{4}{|c|}{ States of nature } \\
\cline { 2 - 5 } & $\mathrm{S}_{1}$ & $\mathrm{~S}_{2}$ & $\mathrm{~S}_{3}$ & $\mathrm{~S}_{4}$ \\
\hline \hline Action 1 & $\mathrm{P}_{11}$ & $\mathrm{P}_{12}$ & $\mathrm{P}_{13}$ & $\mathrm{P}_{14}$ \\
\hline Action 2 & $\mathrm{P}_{21}$ & $\mathrm{P}_{22}$ & $\mathrm{P}_{23}$ & $\mathrm{P}_{24}$ \\
\hline Action 3 & $\mathrm{P}_{31}$ & $\mathrm{P}_{32}$ & $\mathrm{P}_{33}$ & $\mathrm{P}_{34}$ \\
\hline Action 4 & $\mathrm{P}_{41}$ & $\mathrm{P}_{42}$ & $\mathrm{P}_{43}$ & $\mathrm{P}_{44}$ \\
\hline Action 5 & $\mathrm{P}_{51}$ & $\mathrm{P}_{52}$ & $\mathrm{P}_{53}$ & $\mathrm{P}_{54}$ \\
\hline \hline
\end{tabular}

S o u r c e : own study.

where:

$-\mathrm{A}_{\mathrm{i}}$ : Actions or alternatives or options to be selected by the decision-maker;

$-S_{j}$ : States of nature or number of events, on which one has no influence at all;

$-\mathrm{P}_{\mathrm{ij}}$ : the payoff one can get by choosing the i-th action in case of the $\mathrm{j}$-th event occurring.

The payoffs surely affect which option is chosen; the main goal is to observe and describe the effect of it. Since more is always better, there would be no sense to the experiment if only the payoff differed in the choices. Therefore probabilities have to change as well. Examining the effect of the probabilities on the choices can be another aim.

In the decision there is (Luce, Raiffa, 1957, p. 13):

- certainty, when the only existing event occurs by choosing an alternative;

- risk, when lots of outcomes exist for each alternative and there are probabilities that can be ordered to those. Now in the cards example, we had exact probabilities that could be calculated from the numbers of the cards (a priori probabilities). Sometimes these are only estimated based on the frequencies in the past or based on the previous experiments (posteriori probabilities). In the first case one can rely on them with total peace of mind while in the second case the reliability of probabilities can be questioned;

- uncertainty, when lots of outcomes exist for each alternative and there are no probabilities at all that can be ordered to those. At all means, that no conjectures, no ideas, neither mathematical suppositions, nor obse- 
rvations in the past. Obviously one won't face such a situation unless dealing with marginal mathematical problems.

Some (eg. Hansson, 2005, pp. 26-28.) based on the reliabilities of probabilities split up the second case into risk (complete probabilistic knowledge) and uncertainty (partial probabilistic knowledge). Here risk is used in a narrower sense compared to the previous classification. The last case is called ignorance instead of uncertainty (because this is already occupied).

Kahneman and Tversky (1979, p. 265) handled risk as a variable and they showed that people overweight outcomes that are considered certain, relative to outcomes which are merely probable (certainty effect).

Perhaps it is not surprising, that outside the scientific community risk is not something that has strict definitions. However, on the other hand, it must have a meaning. In a survey (Kolnhofer-Derecskei \& Nagy, 2016, pp. 161-172.) the term risk was examined. Respondents were asked to define what risk means to them. They mentioned many examples. The method of content analysis enabled to draw general conclusions from the answers. The most frequently occurring words were displayed in a word cloud.

Figure 1. Cloud diagram of automatic coding

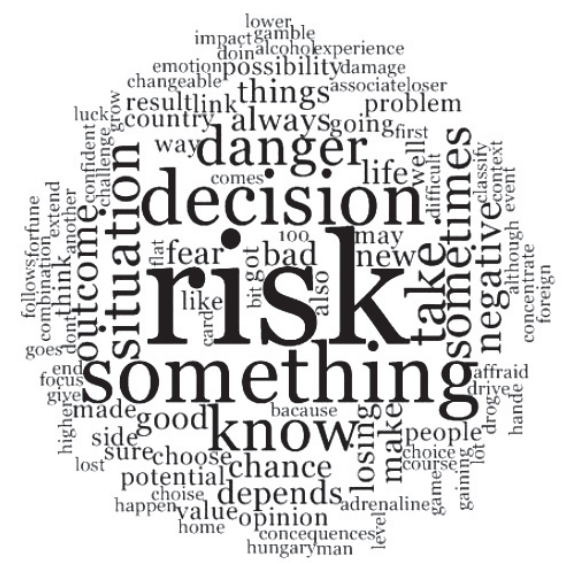

S o u r c e : Kolnhofer-Derecskei, Nagy, 2016, p. 166.

Since the font sizes represent how frequently terms occur they concluded from the word cloud that risk was composed mainly of negative content. 
In my paper I use the term risk in a broader sense since it suits the respondents' perception.

\section{RESEARCH METHODOLOGY AND THE COURSE OF THE RESEARCH PROCESS}

I decided to observe the behavioural pattern by using probabilistic games: these have the two important components mentioned above: payoffs or winnings (concentrating on money) and the probability. Examining real life from that point of view I set up the following matrix with the most characteristic gambles in it:

Figure 2. Probabilities and payoffs

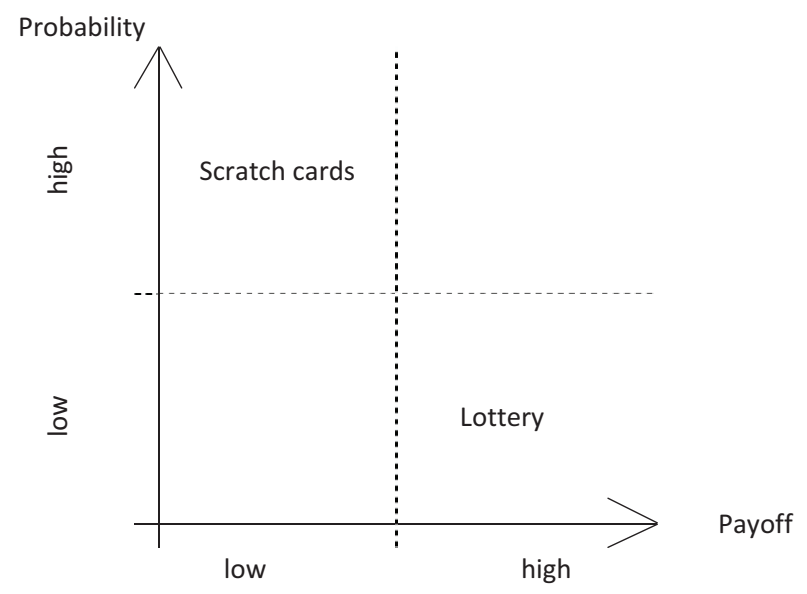

S o u r c e : own study.

Probabilistic games can be used to study preferences. In a research (Kolnhofer-Derecskei \& Nagy, 2017) it was shown that the final benefit of a risky decision will be the biggest influence on respondents. Of course, it is necessary not to omit personality. To exclude the effect of final benefits, in my research the winnings were equal.

Consider the following experiment: suppose, you have a box with 100 balls in it. 25 out of 100 are red, 25 green, the remaining 50 are blue and yellow in an unknown proportion including the opportunity that all of them are either blue or yellow. One ball is drawn out of the box randomly (the balls are of course 
well mixed) and based on the colour of it the following gains can be realised in Hungarian Forint:

Table 3. Payoff table in the research

\begin{tabular}{|c|c|c|c|c|}
\hline \hline Options & Red & Green & Blue & Yellow \\
\hline \hline Alternative 1 & 1000 & 1000 & 1000 & 0 \\
\hline Alternative 2 & 1000 & 0 & 1000 & 1000 \\
\hline \hline
\end{tabular}

S o u r c e : own study.

Which option would you choose? Tick the box.

Alternative $1 \quad \square$ Alternative 2

What if the winnings are in Euro?

Alternative $1 \quad \square$ Alternative 2

The above described case will be referred as Case $\mathrm{X}$, while the following the Case Y. Now, the box and the conditions are the same, but the options have altered. Winnings interpreted in Hungarian forint.

Table 4. Payoff table in the research

\begin{tabular}{|c|c|c|c|c|}
\hline \hline Options & Red & Green & Blue & Yellow \\
\hline \hline Alternative 3 & 0 & 0 & 1000 & 1000 \\
\hline Alternative 4 & 1000 & 0 & 1000 & 0 \\
\hline \hline
\end{tabular}

S o u r c e : own study.

Which option would you choose? Tick the box.

Alternative $3 \quad \square$ Alternative 4

What if the winnings are in Euro?

Alternative $3 \quad \square$ Alternative 4

These questions provide the possibility to examine the following:

- since with minor fluctuation 1 euro equals 300 forints, it can be checked whether the 300 times amount has influence on the risk-taking in both 
cases. I suspected that such a huge difference would have the decision-makers prefer the certain options.

- in both Cases (X and Y), between the options there is one where exact probabilities can be used for calculating the expected value, while regarding the other option, only "from-up to" possibilities can be calculated to be both higher and lower than the other option. Choosing the certain alternative I suppose that the decision-maker is pessimistic, and preferring the risky alternative I suppose indicates optimistic behaviour. It is widely believed that Hungarians are pessimistic. I do not share this statement so my second aim is to confute the negative voices.

- consistency can be checked: distortions in preferences (reversing preferences) can be observed; if based on the data displayed in the first table, the certain alternative is preferred, and at the same time the risky one is preferred in the second table - and vice versa. Both stable and reversing preferences were expected by me; the real question is their proportion.

In these games it can be observed that the winnings are always 1000. The aim was to make the decisions easier by making the tables as transparent as possible. It is clear: the outcomes are either HUF1000/EUR1000 or nothing. So one might calculate the expected values but it does not make sense here; the real key point is the probabilities to win, that's why the focus should be based on them.

In Alternative 1 the worst case is when all of the unknown balls are yellow. Here the probability to win equals 0.5 ; the best case is when all of them are blue: 1 is the probability. In alternative 2 we have a sure probability of 0.75 . In alternative 3 the probability is 0.5 while in alternative 4 it varies on a wide scale: if all the unknown balls are yellow it is only 0.25 ; the best case occurs when all of them are blue: 0.75 . In both Case $\mathrm{X}$ and Case $\mathrm{Y}$ the certain probability is situated right in the middle of the scale on which the unknown probability varies. It seems that with equal chance the unknown probability can be greater or less than the known one. If the decision was between a certain 0.75 and an unknown $0.3-0.8$, who would risk the unknown? Probably no one. That's why in my examples the known probability is on the half way point of the unknown scale, and that's why I suppose that if someone preferred the sure probability to the unknown one, they expect the unknown probability to be higher than the known one. That can be an optimistic approach. In the other hand, if the sure probability is preferred to the unknown one, I suppose the latter one is expected to be lower than the previous one; that is a pessimistic approach. 
Figure 3. Probabilities that can be ordered to alternatives

\begin{tabular}{|c|c|c|c|c|c|}
\hline Options & & & babili & & \\
\hline Alternative 1 & & 1 & & & - \\
\hline (optimistic) & 0 & 0.25 & 0.50 & 0.75 & 1 \\
\hline Alternative 2 & 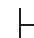 & + & & H & -1 \\
\hline (pessimistic) & 0 & 0.25 & 0.50 & 0.75 & 1 \\
\hline Alternative 3 & H & $t$ & t & 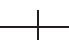 & -1 \\
\hline (pessimistic) & 0 & 0.25 & 0.50 & 0.75 & 1 \\
\hline Alternative 4 & $\mid$ & & & 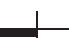 & 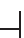 \\
\hline (optimistic) & 0 & 0.25 & 0.50 & 0.75 & 1 \\
\hline
\end{tabular}

S o u r c e : own study.

\section{RESULTS AND CONCLUSIONS}

These above mentioned questions were asked of Hungarian respondents $(\mathrm{N}=89)$ who were studying the Business Development course at master's level.

Table 5. Distribution table

\begin{tabular}{|c|c|c|c|c|c|}
\hline \hline Question 1 & Question 2 & Question 3 & Question 4 & Frequencies & Relative frequencies \\
\hline \hline 1 & 1 & 3 & 3 & 18 & $20.22 \%$ \\
\hline 1 & 1 & 3 & 4 & 2 & $2.25 \%$ \\
\hline 1 & 1 & 4 & 3 & 27 & $1.12 \%$ \\
\hline 1 & 2 & 4 & 3 & 0 & $30.34 \%$ \\
\hline 1 & 2 & 3 & 4 & 1 & $0.00 \%$ \\
\hline 1 & 2 & 4 & 3 & 2 & $2.12 \%$ \\
\hline 1 & 2 & 4 & 4 & 0 & $0.00 \%$ \\
\hline 2 & 1 & 3 & 3 & 1 & $1.12 \%$ \\
\hline 2 & 1 & 3 & 4 & $2.25 \%$ \\
\hline
\end{tabular}


Table 5. Distribution table

\begin{tabular}{|c|c|c|c|c|c|}
\hline \hline Question 1 & Question 2 & Question 3 & Question 4 & Frequencies & Relative frequencies \\
\hline \hline 2 & 1 & 4 & 3 & 1 & $1.12 \%$ \\
\hline 2 & 1 & 4 & 4 & 0 & $0.00 \%$ \\
\hline 2 & 2 & 3 & 3 & 20 & $22.47 \%$ \\
\hline 2 & 2 & 3 & 4 & 1 & $1.12 \%$ \\
\hline 2 & 2 & 4 & 4 & 12 & $1.12 \%$ \\
\hline 2 & \multicolumn{2}{r|}{ Total } & & 89 & $13.48 \%$ \\
\hline
\end{tabular}

S o u r c e : own study.

In figure 4 it is more obvious that some of the possible outcomes are extremely popular and some of them are extremely unpopular.

Figure 4. Frequencies

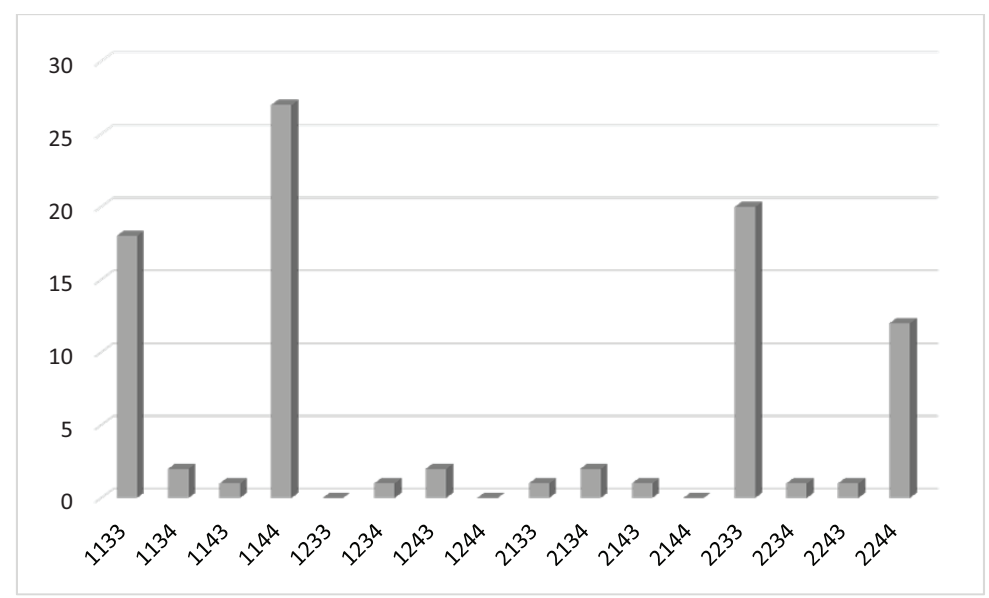

S o u r c e : own study.

Here Yule's Q, which is a specific of Goodman and Kruskal's gamma to 2x2 matrices, can be used as a measure of association between two questions, because both variables (questions) are measured at the nominal level. The values should express the same tendency that is displayed in figure 4. 
Table 6. Yule's Q values

\begin{tabular}{|c|c|c|c|c|}
\hline \hline & Question 1 & Question 2 & Question 3 & Question 4 \\
\hline \hline Question 1 & 1 & 0.9854 & -0.4201 & -0.3731 \\
\hline Question 2 & & 1 & -0.2981 & -0.4161 \\
\hline Question 3 & & & 1 & 0.9613 \\
\hline Question 4 & & & & 1 \\
\hline \hline
\end{tabular}

S o u r c e : own study.

In both Cases ( $\mathrm{X}$ and $\mathrm{Y}$ ) very high values can be observed (0.9854 and 0.9613 ) i.e. there is very strong relationship between the questions.

In Case X 57.30\% took the risk, $42.70 \%$ avoided it, while in Case $Y$ that was $49.44 \%$ and $50.56 \%$ when it was about HUF. When the currency changed to EUR, in Case X 58.43\% took the risk, $41.51 \%$ avoided it, while in Case $Y$ that was $50.56 \%$ and $49.44 \%$.

Table 7. Relative frequencies

\begin{tabular}{|c|c|c|}
\hline \hline Options & Distribution (HUF) & Distribution (EUR) \\
\hline \hline $\begin{array}{c}\text { Alternative 1 } \\
\text { (optimistic) }\end{array}$ & $57.30 \%$ & $58.43 \%$ \\
\hline $\begin{array}{c}\text { Alternative 2 } \\
\text { (pessimistic) }\end{array}$ & $42.70 \%$ & $41.51 \%$ \\
\hline $\begin{array}{c}\text { Alternative 3 } \\
\text { (pessimistic) }\end{array}$ & $49.44 \%$ & $50.56 \%$ \\
\hline $\begin{array}{c}\text { Alternative 4 } \\
\text { (optimistic) }\end{array}$ & $50.56 \%$ & $49.44 \%$ \\
\hline \hline
\end{tabular}

S o u r c e : own study.

These are averages; i.e. on the one hand we know neither whether the same people are standing behind the $57.30 \%$ and the $58.43 \%$, nor do we know, on the other hand, whether the same people created the $57.30 \%$ and the $49.44 \%$.

The effect of changing the currency from HUF to EUR: Those who changed Alternative 1 to Alternative 2 or inversely, have the same cardinality (more precisely only a one-person difference could be observed): the $57.30 \%$ has changed to $58.43 \%$. Interestingly, the same can be stated regarding Alternative 3 and Alternative 4. Those who changed Alternative 3 to Alternative 4 or 
inversely, have the same cardinality with a one-person difference: the $49.44 \%$ has changed to $50.56 \%$.

In Case X, the difference in currency, I mean the 300 times difference in the amount of money, this did not influence the risk-taking in $92.13 \% .53 .93 \%$ took the risk and $38.20 \%$ avoided it. In $7.87 \%$ the preference was reversed: three persons changed their minds from the option of unknown probability to the certain one, while four persons moved in the opposite direction.

In Case $Y$ the difference did not influence the risk-taking in 87.64\%. 43.82\% took the risk and $43.82 \%$ avoided it. In the remaining $12.36 \%$ the preference reserved: six persons changed from the sure-probability alternative to the risky one, while the opposite change could be observed in 5 cases.

In Case $\mathrm{X}$ with lower probabilities compared to those in Case $\mathrm{X}$, the respondents tended more to change preferences. This is indicated by increasing the changers' number from seven to eleven.

Taking a closer look behind the numbers, the following question can be asked: what changes are caused if the respondents are faced with lower probabilities? The effects, when the winnings were in HUF, are the following: 33.71\% opted to take part in the risky situations (optimistic approach) in spite of the decreased probabilities and $26.97 \%$ did not alter their pessimistic approach. On the whole, $60.67 \%$ made consistent decisions. $23.60 \%$ out of the remaining $39.33 \%$ changed from optimist to pessimist and $15.73 \%$ from pessimist to optimist. The difference is huge: the optimist tends to be pessimist by 1.5 times chance more than pessimists tend to change to optimists. The effects, when the winnings were in EUR, were the following: $34.83 \%$ did not change, they were stable optimistic, and $25.84 \%$ proved pessimistic by always preferring the fixed probabilities instead of the risky situations with the unknown probabilities. A total of $60.67 \%$ follow a stable behavioural pattern. The remaining $39.33 \%$ can be split into two groups: $23.60 \%$ who became pessimistic from optimistic, and $15.73 \%$ who became optimistic from pessimistic. Same differences as above. If one compares the proportions referring HUF and that of EUR, only tiny differences can be observed. We can notice that regardless of the currency, people follow their behavioural patterns (they have either stable or reversible preferences but in that they are consistent) in a given situation. The decreasing probabilities affect them in the same way: as they acted for falling probabilities in the case of HUF, they followed the same action in case of EUR.

Regardless of the differences in both amounts and probabilities, $30.34 \%$ of the respondents are optimists. So 30 persons out of 100 are hopeful and expect 
the best that can happen. Against them are the $22.47 \%$ who are pessimists in all circumstances.

\section{SUMMARY}

Admitting the fact that the experiment was not a representative one, still the following conclusions can be drawn.

Firstly, despite this, it is very clear that the first superstition has failed: the willingness to risk-taking is typically not influenced by the 300 times difference in amount since approx. $90 \%$ of respondents did not alter from their original choice. So taking the risk or avoiding it does not depend on the amount itself.

Secondly, in Case X, using HUF there is a 14.60 percentage point difference in favour of the optimists; using EUR it is 16.92 percentage points. Almost identical values. In Case $\mathrm{Y}$ the proportion of optimists and pessimists is almost fifty-fifty. So if there is any trait in the Hungarian nation, it is rather that of a positive attitude; on average, actually rather optimistic. The fact, that 30 persons out of 100 are always optimistic and only 22 are pessimistic, confirms this.

Thirdly, independent from the level of probabilities to win, exactly $60.67 \%$ made consistent decisions in both cases interpreting it within the frame of the currencies. The decisions of the remaining $40 \%$ cannot be forecasted based on their previous choice. That can be a tough challenge for Sales Departments in the market. The aim, to point out that people make inconsistent choices, can be considered to be reached because of this $40 \%$.

\section{ACKNOWLEDGEMENT}

This paper was supported by the ÚNKP-17-4/III. New National Excellence Program of the Ministry of Human Capacities.

\section{REFERENCES}

Allais, M. (1953). Le Comportement de l'Homme Rationnel devant le Risque: Critique des Postulats et Axiomes de l'Ecole Americaine, Econometrica, 21(4). (Oct., 1953), pp. 503-546.

Birnbaum, M. H. (2008). New Paradoxes of Risky Decision Making. Psychological Review, 115(2), April 2008, 463-501. http://dx.doi.org/10.1037/0033-295X.115.2.463.

Hansson, S. O. (2005). Decision Theory A Brief Introduction. Department of Philosophy and the History of Technology, Royal Institute of Technology (KTH) Stockholm, 
http://web.science.unsw.edu.au/ stevensherwood/120b/Hansson_05.pdf (accessed: 27.05.2017).

Kolnhofer-Derecskei, A., \& Nagy, V. (2016). Under Risk. In: Reicher Regina Zsuzsanna (Ed.) FIKUSZ 2016 - Symposium for Young Researchers: Celebration of Hungarian Science 2016: Budapest, 25th november 2016: Proceedings of FIKUSZ 2016.

Kahneman, D., \& Tversky, A. (1979). Prospect Theory: An Analysis of Decision under Risk. Econometrica, 47(2), pp. 263-292.

Kolnhofer-Derecskei, A., \& Nagy, V. (2017): Comparing risk definitions given by Hungarian and Belgian Bachelor Students. In: Thinking Together (under publishing) 14 pages.

Luce, R Duncan \& Raiffa, H. (1957): Games and Decisions, John Wiley and Sons, Inc.

Neumann, von J., \& Morgenstern, O. (1953), Theory of Games and Economic Behavior, Princeton University Press, Fifth printing (third edition). 